Kiryoku, Volume 3 No 32019

e-ISSN: 2581-0960 p-ISSN: 2599-0497

Tersedia online di http://ejournal.undip.ac.id/index.php/kiryoku

\title{
WAJAH JEPANG PADA ERA HEISEI
}

\author{
Maharani Patria Ratna \\ Sekolah Vokasi, Universitas Diponegoro, Jl. Prof. Soedarto, SH, Kampus Undip Tembalang, \\ Semarang, Indonesia 50275 \\ maharanipatria@live.undip.ac.id
}

\begin{abstract}
Abstrak
Era Heisei telah berubah menjadi era Reiwa pada tahun 2019. Semua orang Jepang memasuki fase baru dari era kekaisaran Jepang. Kaisar Akihito ingin turun tahta karena alasan kesehatan, sehingga tahta digantikan oleh kaisar Naruhito. Penelitian ini bertujuan untuk melihat kembali peristiwa penting yang terjadi di era Heisei. Metode yang digunakan adalah penelitian ini adalah penelitian deskriptif kualitatif. Data dikumpulkan dengan metode literatur melalui beberapa artikel tentang era Heisi. Hasil penelitian ini menunjukkan bahwa secara keseluruhan dapat dikatakan bahwa perdamaian telah tercapai di Jepang. Era Heisei adalah era yang penuh dengan gejolak ekonomi dan bencana di Jepang. Selain itu, era Heisei juga masih menyisakan tugas berat bagi era Reiwa, yaitu perbaikan ekonomi setelah gelembung ekonomi untuk menghidupkan kembali ekonomi Jepang seperti sebelumnya. Era Heisei memang penuh tantangan bagi Jepang, tetapi kepercayaan internasional terhadap Jepang sangat tinggi. Dengan memajukan kemajuan teknologinya, Jepang berhasil menjadi penyelenggara olimpiade musim dingin pada tahun 1998 dan piala dunia pada tahun 2002 .
\end{abstract}

Kata kunci: Heisei, Jepang, Gelembung Ekonomi, Reiwa, Kaisar

\begin{abstract}
The Heisei era had changed to the Reiwa era in 2019. All the Japanese people entered a new phase of the Japanese imperial era. Emperor Akihito wanted to abdicate for health reasons, so the throne was replaced by emperor Naruhito. This study aims to look back at any significant events that occurred in the Heisei era. The method used is this research is a qualitative descriptive study. Data collected by the literature method through several articles about the Heisi era. The results of this study indicates that overall it can be said that peace has been achieved in Japan. The Heisei Era is an era filled with economic turmoil and disasters in Japan. In addition, the Heisei era also still leaves a heavy task for the Reiwa era, that is economic improvement after the economic bubble to revive the Japanese economy as before. Heisei era is indeed full of challenges for Japan, but international confidence in Japan is very high. By advancing its technological progress, Japan managed to become the organizer of the winter olympics in 1998 and the world cup in 2002.
\end{abstract}

Keywords: Heisei; Japan; Economy Bubble; Reiwa; Emperor 
Kiryoku, Volume 3 No 32019

e-ISSN: 2581-0960 p-ISSN: 2599-0497

Tersedia online di http://ejournal.undip.ac.id/index.php/kiryoku

\section{Pendahuluan}

Era Heisei atau Heisei jidai (平成時代) baru saja berlalu dan digantikan dengan era Reiwa (令和). Heisei sendiri merupakan era yang menggambarkan harapan masyarakat Jepang akan terwujudnya perdamaian. Hal ini secara sederhana dapat diamati secara harfiah melalui kanji hei (平) dansei (成) pada kata "Heisei”. Hei berarti 'damai' dan sei berarti 'menjadi'. Pada awal era Heisei, Kaisar Akihito naik tahta pada tahun 1989 menggantikan kaisar Hirohito yang meninggal pada 8 Januari 1989.

Artikel mengenai era Heisei pernah ditulis sebelumnya oleh Hanley dan Treat (1997), yakni mengenai kesinambungan dan perubahan pada era Showa ke era Heisei. Dalam artikelnya, keduanya memuat berbagai pendapat para ahli yang memberikan pendapat sesuai bidangnya mengenai hal-hal yang telah dilalui pada era Showa dan perkembangan yang diprediksi pada era Heisei. Selain itu Lebra (1997) mengangkat tema mengenai transisi perubahan budaya keluarga kerajaan pada era Showa menjadi era Heisei. Hasil dari penelitiannya menyebutkan bahwa walaupun terdapat sedikit perbedaan budaya pada keluarga kerajaan era Showa dan era Heisei namun perbedaan tersebut bukanlah suatu revolusi budaya keluarga kerajaan.

Penelitian ini sama-sama mengangkat tema mengenai era Heisei di Jepang, namun jika pada penelitian sebelumnya mengangkat tema mengenai perubahan pada era Showa ke era Heisei dan mengenai transisi perubahan budaya keluarga kerajaan pada era Showa menjadi era Heisei, maka penelitian ini lebih terfokus kepada mendeskripsikan segala hal penting yang terjadi di Jepang pada era Heisei. Tujuan dari penelitian ini adalah mendeskripsikan Jepang selama era Heisei.
Melalui deskripsi tersebut diharapkan tergambarkan poin pentingyang menjadi wajah Jepang pada era Heisei sehingga dapat menjadi sarana pembanding Jepang pada era Heisi dan era Reisei nantinya. Dalam penelitian ini dapat dilihat pula apakah era Heisei yang diharapkan membawa Jepang menjadi negara yang damai telah tercapai.

\section{Metode}

Penelitian ini menggunakan metode deskriptif melalui pendekatan kualitatif. Untuk melakukan penelitian ini, dilakukan tiga tahapan, yakni tahap pengumpulan data, tahap analisis data, dan tahap penyajian hasil. Metode yang digunakan untuk mengumpulkan data adalah metode kepustakaan. Metode kepustakaan merupakan metode penelitian yang bertujuan untuk mengumpulkan data dan informasi dengan bantuan bermacammacam material yang terdapat di ruangan perpustakaan, seperti buku-buku, majalah, dokumen, catatan dan kisah-kisah sejarah dan lain-lain (Mardalis, 1999: 28). Teknik yang digunakan adalah teknik dokumentasi, yaitu teknik pengumpulan data melalui text reading, pengkajian, dan pencatatan segala pustaka yang berhubungan dengan penelitian ini.

Sebagai upaya untuk mengumpulkan data, penulis mendokumentasikan beberapa sumber tertulisserta melakukan penyimakan terhadap pencapaian Jepang pada era Heisei. Sumber tertulis yang dikaji dan disimak adalah berupa artikel jurnal, buku, artikel berita, dll. Tahap selanjutnya yakni tahap analisis. Data dianalisis dengan metode deskriptif kualitatif. Dengan menggunakan data yang terkumpul, penulis akan mendeskripsikanJepang pada era Heisei.

Hasil yang dicapai dalam penelitian ini akan disajikan dalam bentuk deskripsi. Melalui proses di atas, diharapkan tujuan 
dalam penelitian ini dapat tercapai. Deskripsi akan disajikan melalui berbagai bidang, diantaranya adalah bidang pendidikan, politik, ekonomi, dll. Melalui sudut pandang dari bidang-bidang tersebut, akan dideskripsikan sebuah simpulan mengenai Jepang pada era Heisei. Simpulan dibuat berdasarkan analisis kritis fenomena-fenomena penting yang terjadi selama era Heisei. Simpulan ini nantinya akan menjadi sebuah deskripsi untuk melihat Jepang selama era Heisei.

\section{Hasil dan Pembahasan}

\subsection{Era Heisei}

Nama Heisei pada awalnya diusulkan bersamaan dengan dua nama era lainnya sebagai pengganti era Showa, yakni Shubun (修文) dan Seika (正化). Namun keduanya sejak awal dianggap bukan kandidat kuat pengganti era Showa, mengingat era Showa diawali huruf "S", sehingga Jepang membutuhkan era dengan nama huruf depan yang berbeda untuk membedakan penulisan penanggalan di Jepang.Era Heisei merupakan pengganti era Showa yang berakhir pada tahun 1989 . Era Heisei dipimpin oleh putra mendiang kaisar Hirohito, yakni kaisar Akihito pada waktu itu. Kaisar Akihito telah bertahta selama 30 tahun yakni sejak 1989 hingga 2019.

Kaisar Akihito sendiri dinobatkan sebagai kaisar ke-125 Jepang yang naik tahta sehari setelah kaisar Hirohito meninggal. Walaupun secara prosedural kaisar Akihito masih harus bertahta, namun karena alasan kesehatan beliau tidak dapat melanjutkan tugasnya. Oleh karena itu, pada tahun 2019 diputuskan dimulai era Reisei sebagai pengganti era Heisei dengan kaisar Naruhito sebagai pengganti kaisar Akihito. Era Heisei sendiri pada dekade pertama merupakan dekade yang tidak seberat dekade-dekade sebelumnya pada era Showa. Hal tersebut dinilai wajar karena era Showa (1926 1989) merupakan era pemulihan dan era pertumbuhan ekonomi global Jepang pasca kekalahan pada perang dunia kedua (1939 - 1945).

Era Heisei sendiri merupakan era dimana pemerintahan Jepang dipimpin oleh 15 orang Perdana Menteri. Selama itu banyak sekali terjadi perlambatan ekonomi yang berkepanjangan dan krisis finansial.Pada beberapa tahun awal dimulainya era Heisei terjadi banyak musibah di Jepang, diantaranya adalah gempa bumi di Kobe serta serangan gas mematikan oleh sekelompok sekte keagamaan di Jepang. Bahkan pada 2011 terjadi gempa besar dan Tsunami di timur laut Honshu yang juga memicu kecelakaan nuklir Fukushima. Namun, diantara berbagai bencana yang terjadi di era Heisei, adapun beberapa peristiwa yang menjadi suka cita rakyat Jepang, yakni pernikahan putra mahkota Naruhito dan putri Masako pada tahun 1993, olimpiade musim dingin tahun 1998 di Nagano, diselenggarakannya piala dunia di Jepang dan Korea pada tahun 2002, dll.

\subsection{Jepang Pada Era Heisei}

Dilihat melalui beberapa bidang, berikut ini adalah segala hal yang terjadi di Jepang selama era Heisei.

1. Bidang Pendidikan

Dibandingkan era sebelumnya, pendidikan di Jepang dikenal memiliki tuntutan yang lebih tinggi. Oleh karena itu, pada era Heisei banyak pelajar Jepang merasa tidak dapat memenuhi tingkat pendidikan di Jepang sehingga banyak yang bunuh diri. Bahkan selama tahun 2016 - 2017 tercatat 250 lebih anak-anak usia sekolah hingga sekolah menengah melakukan bunuh 
diri. Angka ini meningkat lima kali lipat daripada yang terjadi di tahun 1986. Berbagai persoalan melatarbelakangi terjadinya fenomena bunuh diri tersebut, diantaranya adalah mengenai masalah keluarga, perundungan di sekolah, serta kekhawatiran terhadap masa depan dikarenakan target pendidikan tidak dapat terpenuhi.

2. Bidang Ekonomi

Dalam bidang ekonomi fenomena gelembung ekonomi Jepang sempat menjadi wajah bidang ekonomi Jepang pada era Heisei. Pada tahun 1985 ekonomi Jepang melejit pesat. Harga saham, harga tanah, dan harga rumah misalnya meningkat tajam. Yen pun sempat menjadi mata uang terkuat di dunia. Namun hal tersebut tidak bertahan lama, pada tahun 1990-an Jepang menemui kesulitan berupa banyaknya kredit macet, kebangkrutan berbagai perusahaan, dan krisis ekonomi. Bahkan keadaan tersebut dianggap sebagai keadaan perekonomian Jepang yang terburuk sejak akhir 1940.

3. Bidang politik

Pada era Heisei, gebrakan politik Jepang terjadi pada tahun 1994 yakni reformasi pemilu dan pada tahun 2001 yakni reformasi administrasi. Pada tahun 1994 gebrakan dibuat oleh para reformator dalam sistem pemilu di Jepang bertujuan untuk membentuk suatu sistem baru agar terdapat dua partai yang berkuasa secara bergantian di Jepang. Hal ini berarti partai yang memenangkan pemilu akan dapat membentuk pemerintahan bahkan tanpa partai koalisi, serta pembuatan kebijakan dapat dilaksanakan lebih efisien yakni dengan sistem top-down dari perdana menteri ke semua menteri dalam kabinet. Sementara itu pada reformasi administrasi berfokus kepada penguatan peran kantor perdana menteri dan perampingan birokrasi. Reformasi ini berusaha memberikan kekuasaan kantor perdana menteri pada bidang administrasi untuk memberikan prioritas politik daripada harus tunduk kepada kementerian. Secara konkret hal ini dilakukan dengan memperluas sekretariat kabinet, mendirikan kantor kabinet baru, serta perdana menteri diberikan kekuasaan untuk menunjuk menteri kabinet.

4. Bidang Teknologi

Pada era Heisei, Teknologi Jepang dianggap sebagai yang paling maju di dunia. Penggerak terpenting teknologi Jepang pada era Heisei ditandai dengan revolusi industri 4.0 dengan maraknya Artificial Intelligence (AI) atau intelejensi buatan dan Internet of Things (IoT) atau Internet untuk segalanya. Keduanya menembus batas dunia fisik dan dunia digital di Jepang hingga mampu membuat tatanan baru untuk industri di Jepang. Hal ini menyebabkan perkembangan perangkat keras dan teknik mesin di Jepang mengalami penyusutan. Sebaliknya, hal tersebut justru digantikan oleh perangkat lunak dan inovasi berbasis inovasi seiring dengan meluasnya penggunaan internet setelah pergantian abad.

5. Bidang Kependudukan

Dalam bidang kependudukan, menurut laporan kementerian dalam negeri Jepang (2019), pada era Heisei populasi anak di Jepang menurun sepertiga. Bahkan disebutkan bahwa populasi anak di bawah 15 tahun diperkirakan hanya berjumlah 15,33 juta pada 1 April.Angka tersebut mengalami penurunan sebanyak 180.000 dari tahun sebelumnya dan merupakan angka terendah sejak tahun 1950. Bahkan data jumlah anak yang dirilis sebelum hari anak di Jepang 
menyebutkan bahwa jumlah populasi anak adalah sebanyak $12,1 \%$ dari jumlah keseluruhan populasi Jepang. Hal ini menunjukkan bahwa terdapat penurunan $0,2 \%$ dari tahun ke tahun. Sejak dimulainya era Heisei total penurunan populasi anak adalah sekitar dua pertiga dari 23,2 juta anak pada tahun 1989.

\subsection{Peristiwa-peristiwa Penting Era Heisei}

Selama era Heisei banyak sekali kejadian-kejadian penting yang terjadi. Berikut ini adalah tabel yang menunjukkan peristiwa-peristiwa penting yang terjadi selama era Heisei

\begin{tabular}{ll} 
Tabel 1 Peristiwa Penting Era Heisei \\
\hline Tahun & Peristiwa \\
\hline $\mathbf{1 9 8 9}$ & Bergantinya era Showa menjadi era \\
& Heisei \\
$\mathbf{1 9 9 0}$ - 1991 & Terjadi fenomena gelembung ekonomi \\
$\mathbf{1 9 9 5}$ & Gempa di Kobe \\
& serangan gas mematikan oleh \\
& sekelompok sekte keagamaan \\
$\mathbf{1 9 9 6}$ & Penemuan teknologi pager oleh \\
$\mathbf{1 9 9 7}$ & Jatuhnya gelembung ekonomi \\
$\mathbf{1 9 9 8}$ & Olimpiade musim dingin tahun 1998 \\
$\mathbf{2 0 0 0}$ & Erupsi di Pulau Miyake \\
$\mathbf{2 0 0 2}$ & Pengembalian korban warga Jepang oleh \\
& Korea Utara \\
$\mathbf{2 0 0 9}$ & Piala dunia Jepang dan Korea \\
& Terjadinya penurunan populasi dengan \\
& tajam \\
$\mathbf{2 0 1 1}$ & Berkuasanya parati Demokrat \\
$\mathbf{2 0 1 2}$ & Terjadi Gempa dan Tsunami besar \\
$\mathbf{2 0 1 4}$ & Pembukaan Tokyo Skytree \\
$\mathbf{2 0 1 6}$ & Letusan Gunung Ontake \\
& Pembukaan jalur Shinkansen ke \\
$\mathbf{2 0 1 7}$ & Hokkaido \\
$\mathbf{2 0 1 9}$ & Populernya permainan Pokemon \\
& Lahirnya seekor bayi Panda di kebun \\
& binatang Ueno \\
& Disahkannya RUU imigrasi Jepang \\
& Dimulainya era Reiwa \\
\hline
\end{tabular}

Berdasarkan uraian di atas, dapat diketahui bahwa banyak peristiwa penting yang terjadi di Jepang selama era Heisei. Secara umum perdamaian di Jepang telah terwujud. Namun tidak demikian untuk hubungan Jepang dengan dunia internasional, terutama dengan Korea Utara. Selain hubungan dengan Korea Utara, Jepang juga masih memiliki masalah terutama di bidang kependudukan. Untuk mengatasi masalah tersebut sejauh ini pemerintah Jepang mulai melonggarkan akses imigran agar dapat bekerja di Jepang mengingat penduduk usia produktif di Jepang jumlahnya semakin sedikit.

\section{Simpulan}

Berdasarkan uraian di atas, maka dapat ditarik simpulan bahwa secara keseluruhan dapat dikatakan bahwa perdamaian telah tercapai di Jepang meskipun masih ada ketengangan hubungan dengan negara lain. Era Heisei merupakan era yang penuh dengan gejolak ekonomi dan bencana di Jepang. Selain itu era Heisei juga masih menyisakan tugas berat untuk era Reiwa yakni perbaikan ekonomi pasca peristiwa gelembung ekonomi untuk membangkitkan ekonomi Jepang seperti sedia kala. Era Heisei juga merupakan era yang dianggapbertanggung jawab atas penurunan jumlah penduduk di Jepang, terutama jumlah penduduk usia produktif dan anak-anak. Selain itu, agar jumlah penduduk tidak terus menurun maka pemerintah Jepang wajib memberikan solusi terhadap fenomena bunuh diri yang sering terjadi di Jepang.

Selain beberapa hal di atas, Heisei juga merupakan era di mana teknologi Jepang mengalami kemajuan yang pesat. Selain itu, Jepang juga mendapatkan kehormatan sebagai penyelenggara olimpiade musim dingin tahun 1998 dan sebagai salah satu penyelenggara piala dunia bersama dengan Korea pada tahun 2002. Meskipun Heisei bukanlah era yang mudah bagi Jepang namun kepercayaan dunia internasional 
Kiryoku, Volume 3 No 32019

e-ISSN: 2581-0960 p-ISSN: 2599-0497

Tersedia online di http://ejournal.undip.ac.id/index.php/kiryoku

kepada Jepang masih terbukti tinggi. Majunya teknologi Jepang dan tingkat kriminalnya yang rendah menjadikan Jepang mendapat kepercayaan untuk menyelenggarakan acara berskala internasional.

\section{Daftar Pustaka}

Hanley, Susan B dan John Whittier Treat. 1997. Symposium on Continuity and Change in Heisei Japan. Society For Japanese Studies: Washington

Kobayashi, Nobuko. 2019. Japan EntersReiwa Era With New Identity. Japan Spotlight:

Tokyo

Koran-Jakarta.com. (8 Mei 2019). Populasi Anak di Jepang Menurun Selama Era Heisei. Diakses pada 14 September 2019, dari http://www.koran- jakarta.com/populasi-anak-di-jepangmenurun-selama-era-heisei/

Lebra, Takie Sugiyama. 1997. Self and Other in Estemeed Status. Society For Japanese Studies: Washington

Lincoln, Edward J. 2011. The Heisei Economy: Puzzles, Problems, Prospects. Society For Japanese Studies: Washington

Mardalis. 1999. Metode Penelitian Suatu Pendekatan Proposal. Jakarta: Bumi Aksara

Satoshi, Machidori (25 Maret 2019). 2019. Politics in the Heisei Era. Dikutip 14 September 2019 dari Nippon:https://www.nippon.com/en /in-depth/d00474/politics-in-theheisei-era-big-fixes-but-still-

flawed.html

www3.nhk.or.jp.Looking Back on Heisei. Diakses pada 14 September 2019, dari

https://www3.nhk.or.jp/nhkworld/nh knewsline/lookingbackonheisei/ 